Strength is a physical quality of wood that varies in the same species several hundred per cent. The microscope will often reveal what the timber-testing machine conclusively proves to be the condition of the woody tissues in a piece of timber. Unfortunately, the testing machine cannot be applied to the wood of living trees, but small fragments may be removed from a standing tree for microscopic study without endangering the life of the tree. The microscopic structure of wood. gives a clue to its strength and other valuable qualities, and hence the timber breeder of the future will no doubt have a laboratory equipped with microscopes and accessories for the study of the cellular structure of his trees. It is a well-known fact that the stiffness of a piece of wood is dependent upon the thickness of its cell walls and that resistance across the grain to destructive rupture depends to a great degree upon uniformity in size of the cells. Wood having great tensile strength is made of long cell fibers, while wood with great elasticity usually has very uniformly fine grain.

The user of wood determines what physical qualities are technically most important, the timber tester determines the measure of these qualities, and it remains for the breeder to intensify or improve these qualities. While it takes many years of experiment to determine how far a definite quality in a forest tree is transmissible by heredity, the evidence that the physical qualities of timber are hereditary is sufficiently strong to warrant foresters in making some efforts to select their seed trees along this line. Since the majority of the desirable qualities can be identified by the unaided eye of the close observer; it would seem that there is no valid reason why foresters should continue to ignore such a promising field.

\title{
REPORT OF COMMITTEE ON BREEDING FISH.
}

Joнn W. Tirсомв, Lyndonville, Vermont.

Experiments in reference to the hybridization or crossing of allied species have been continued at several stations of the United States Bureau of Fisheries. While the results have almost invariably been disappointing, it may be of future interest to record some of them. 
Some hybridization experiments of the United States Bureau of Fisheries during the years 1907-1900.

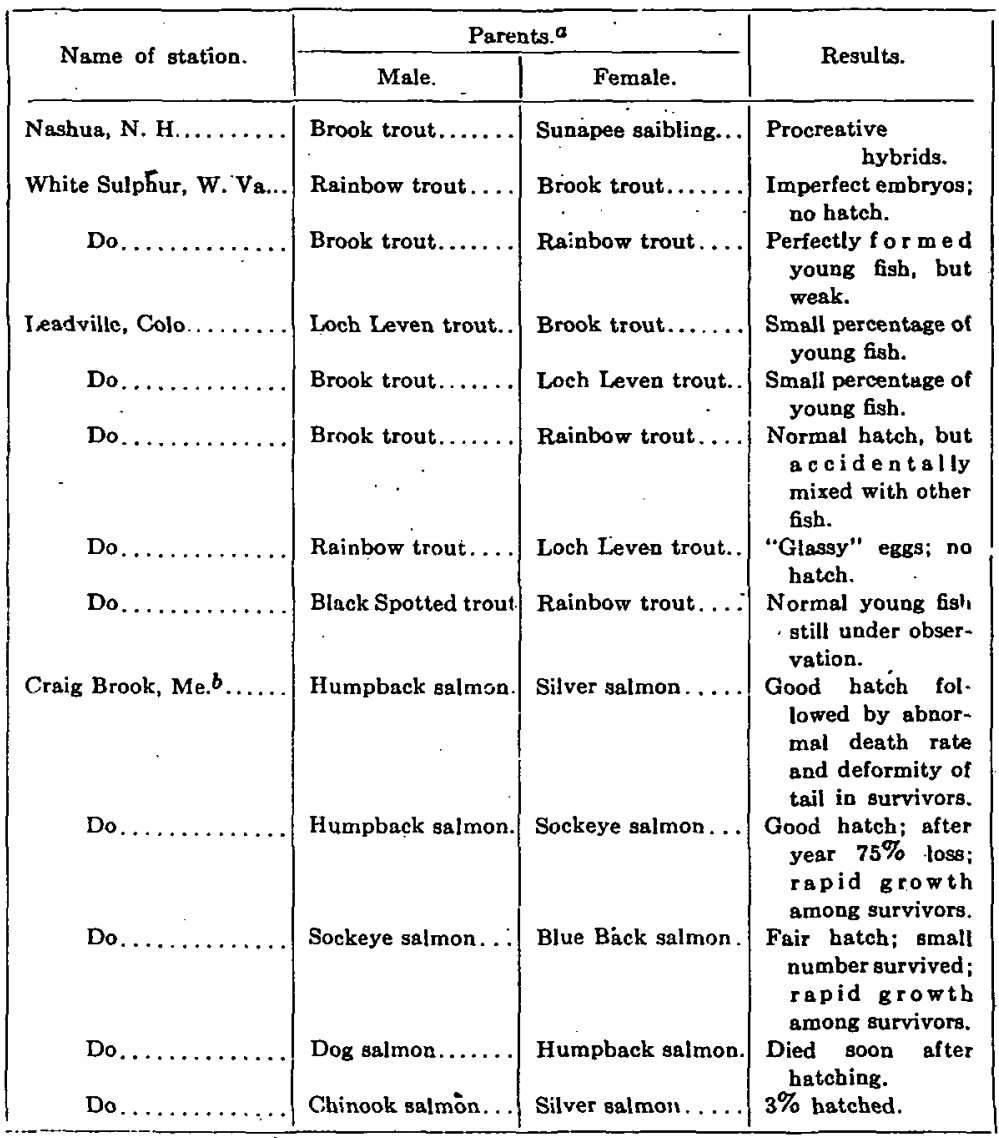

Some of the above experiments have not been carried far enough to determine whether the hybrids are procreative. None of them have produced a hybrid superior to either of their progenitors. Of the Pacific salmon hybrids, the two showing rapid growth encourage a continuation of the observations until it has been determined whether they will mature and reproduce. The salmons all show a remarkable susceptibility to the throat tumor disease.

- Brook trout, 8. fontinalis; Sunapee saibling, 8. aureolus; Rainbow trout, probably s. irtdeus; Loch Leven trout, s. trutta levenensis; Black Spotted trout, one of the native trouts of the Rocky Mountains.

- The Pacific salmon hybrids hatched at Cralg Brook, Me., were from eggs obtalned on tributarles of the Skagit River, State of Washington. 
A great many similar experiments in hybridization have been conducted in the United States of which the observations have not been carried far enough or the results did not warrant it.

Experiments in the crossing and hybridizing of various species of salmonidæ have been made in Scotland and several European countries. Both the Rainbow and the eastern Brook trouts of America have been crossed with the European trouts at various fish-culture establishments. Impregnation is readily accomplished, but in all the efforts to hybridize the trouts and salmon of Europe, as well as in the crossing of American with European species of trouts, it appears to be regarded as established that, while there is a development, it soon reaches its end or leads to malformations. Some of the hybrids are procreative, but in general the results have been disappointing, and foreign fish culturists appear to have discontinued breeding experiments of this character.

It seems useless to continue the experiments until an experiment station has been established where hybridization and other experiments can be systematically conducted under scientific observation and carried to a definite conclusion.

The experiment inaugurated at the Northville station in selecting and breeding for specific bacterial immunity in Brook trout has resulted in failure, the 20,000 fish held for the purpose having succumbed to the disease.

The committee is not entirely discouraged by the failures here reported, but is unanimous in the opinion that few if any satisfactory results can be obtained until one or more experiment stations have been established at which the work can be conducted unhampered by the regular fish-cultural work that is the necessary and legitimate work of the existing State and Federal hatcheries.

The necessity for experiment stations to advance strictly fishcultural work is quite as important as for experiments in breeding. However, fish culture and fish breeding are so interdependent that one experiment station could be utilized in the advancement of both. 